\title{
Spanish and Swedish teachers' perspective of teaching STEM and robotics in preschool - results from the botSTEM project
}

\author{
Marie Fridberg $^{1}$ (D) Andreas Redfors ${ }^{1}$ (D) - Ileana M. Greca ${ }^{2}$ (D) Eva M. García Terceño ${ }^{2}$ (D)
}

Accepted: 13 November 2021 / Published online: 4 January 2022

(c) The Author(s) 2022

\begin{abstract}
This article describes outcomes from the Erasmus + project botSTEM, involving a theoretical framework for Science, Technology, Engineering \& Technology (STEM) and robotics and teaching activities for preschool teachers and teachers educating children 4-8 years old. Spanish and Swedish preschool teachers' self-efficacy and views of teaching STEM and robotics are presented, using a mixed methodology based on a questionnaire and focus group interviews. The 3-year long project has improved the preschool teachers' self-efficacy in STEM and robotics teaching, as described in a questionnaire answered by the preschool teachers after the project. Possibilities in STEM and robotics teaching experienced by them include an increase in children's agency, knowledge and interest, and the obstacles are mainly structural or technical. Robotics teaching also supports children with special needs when interacting with peers. The results from the botSTEM project point to the benefit of supported long-term professional development for STEM and robotics teaching in preschools.
\end{abstract}

Keywords STEM · Robotics · Preschool teachers · Professional development $\cdot$ Self-efficacy

\section{Introduction}

Increasing attention is directed towards STEM programmes because of their efficiency in developing scientific literacy for citizens and interest among young people for studies in scientific-technological disciplines (EU, 2015; NRC, 2012, 2014). When STEM teaching

Andreas Redfors

andreas.redfors@hkr.se

Marie Fridberg

marie.fridberg@hkr.se

Ileana M. Greca

imgreca@ubu.es

Eva M. García Terceño

emgterceno@ubu.es

1 Faculty of Education, LISMA, Kristianstad University, 29188 Kristianstad, Sweden

2 Departamento de Didácticas Específicas, Facultad de Educación, Universidad de Burgos, C/Villadiego, 1, 09001 Burgos, Spain 
focuses on real-world problems and societal issues integration of two or more of the STEM disciplines becomes natural, the concept of 'integrated STEM' has emerged (Ortiz-Revilla et al., 2020). Integrated STEM is also suitable for early years teaching (Greca Dufranc et al., 2020; Honey et al., 2014; MacDonald et al., 2020). However, only a few theoretical frameworks for integrated STEM teaching exist (Greca Dufranc et al., 2020; Ortiz-Revilla, Greca, \& Arriassecq, 2021a, 2021b), and the teaching guidelines are often not theoretically framed and specific enough for teachers' implementation (Chu et al., 2019). Furthermore, while children in elementary school often have an interest in STEM disciplines, they often lose this positive attitude as they grow older (Ali et al., 2013; Denessen et al., 2015; DeWitt \& Archer, 2015). Research (cf. Tytler \& Osborne, 2012) points out that early childhood intervention constitutes a good opportunity to generate positive attitudes to STEM.

The ERASMUS + project Robotics and STEM education for children and primary schools (botSTEM) with partners in Spain (coordinators), Sweden, Italy and Cyprus, has been reported on earlier (cf. Greca Dufranc et al., 2020 where the theoretical framework for the project is described in detail). botSTEM developed a research- and evidence-based toolkit with teaching guidelines for teachers working with integrated STEM and scaffolded by robotics in preschool and primary school (children 4-8 years old). botSTEM explicitly addresses computational thinking (by means of robotics), which is regarded as valuable for its potential to teach logical thinking, problem solving and digital competence at early childhood. So, robotics and coding are viewed as a part of STEM per se, but the botSTEM project was focused on STEM teaching with explicit scaffolding by robotics and coding. As stated above, STEM in early childhood education should preferably be holistic, childcentred, and problem based. Child-centred hands-on STEM experiences in early childhood positively affect their perceptions and dispositions towards STEM (Bagiati et al., 2010; Bybee \& Fuchs, 2006; DeJarnette, 2012; Kermani \& Aldemir, 2015; Ortiz-Revilla, Greca and Meneses, 2021). To reach this integration, two methodologies, inquiry teaching and engineering design, was intertwined in the botSTEM activities in order to integrate the different disciplines of STEM through real world problems, the solution of which should involve also activities related to computational thinking, by means of robotics or coding. Figure 1 outlines this didactical framework. This combined use of both methodologies, framed in a rich environment, fosters the development of STEM abilities.

Teachers in the project were part of planning discussions with researchers about the botSTEM pedagogical framework (Greca Dufranc et al., 2020) and thereafter the teachers chose and tried out different activities from the toolkit. The pedagogical framework of botSTEM was, for the implementation, complemented by teaching principles following variation theory in the planning discussion with the preschool teachers. The core idea of variation theory (Marton, 2014; Marton \& Booth, 1997) is that learning is always directed at something specific called the object of learning. Furthermore, learning is viewed as a qualitative change in the way of experiencing the object of learning, and ways of acting originate from ways of experiencing (Marton \& Tsui, 2004).

To experience an object of learning requires that the learner becomes aware of its different aspects, and is provided opportunity to discern these aspects simultaneously. Aspects that are critical to the intended way of experiencing the object of learning for a given learner are called critical aspects. An object has many aspects, and not all aspects are critical for all students. To give an example (Fridberg et al., 2017), the concept of water evaporation was abstract for the involved preschool children until the teacher boiled water, pointing out the visible vapor rising from the kettle. Thereby, the visible vapor can be described as a critical aspect for the involved children to experience evaporation. Learners need to be given opportunity to experience aspects that are critical for them. For every object of 


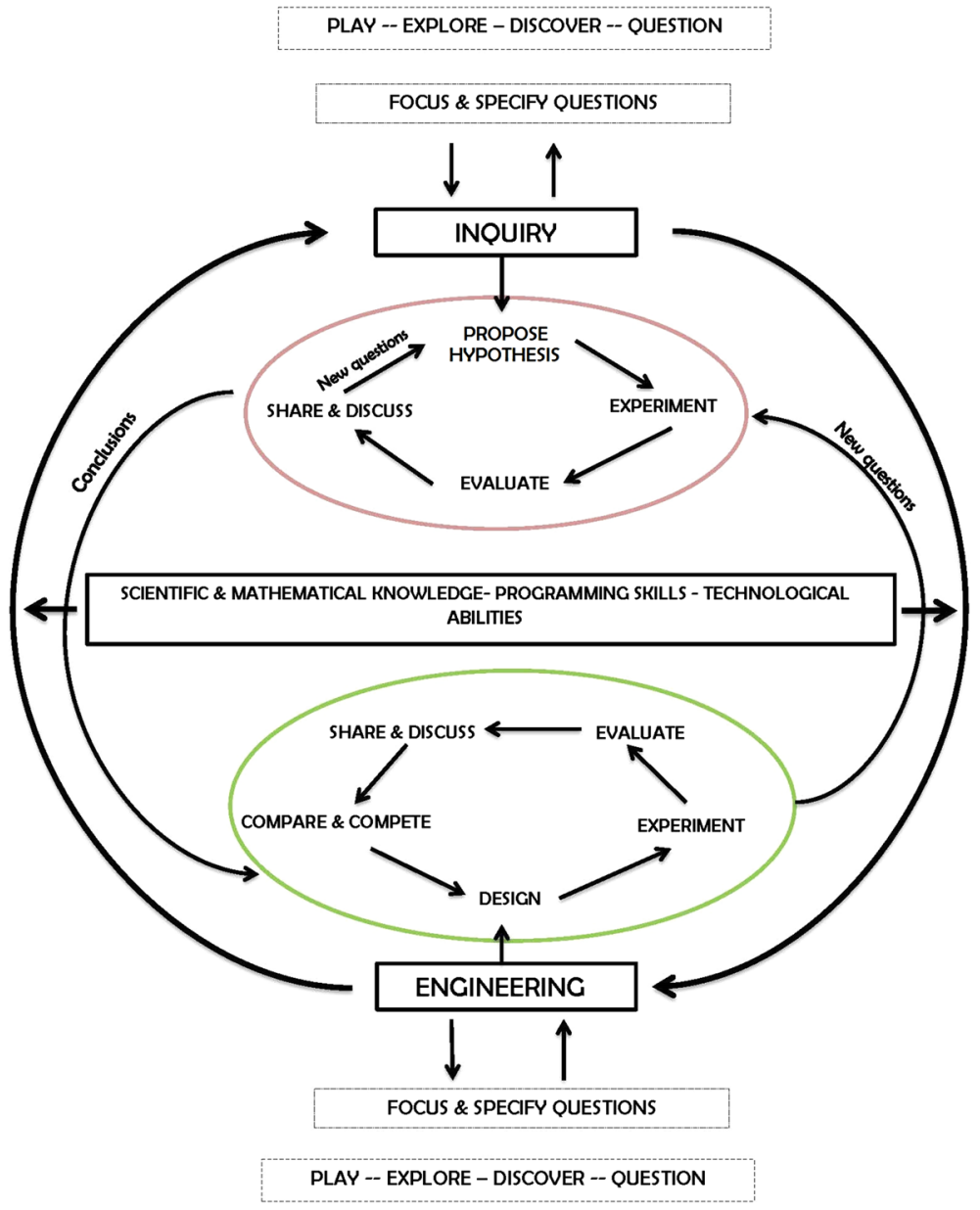

Fig. 1 botSTEM didactical model developed for introducing integrated STEM education at elementary grades (Greca Dufranc et al., 2020)

learning and for every learner there are critical aspects that the learners must be able to discern.

The object of learning is not stationary. It can be, and is, discussed and experienced in three different ways. The intended object of learning planned by the teacher, the enacted object of learning that the teacher implements in the classroom situation, and the lived object of learning what the learners actually experience. All three are experienced differently (Marton \& Tsui., 2004).

At the pedagogical level, this theory allows teachers to delve into the analysis of what they want to teach and, in this sense, it is a good strategy both for introducing innovations in the teaching and for analysing the changes experienced by the teachers. It allows to clearly identify which are the critical aspects of the object of learning, and in this way facilitate and guide the design of a teaching sequence that directs students towards the intended object of learning. Hence, it can be understood as a pedagogical planning tool (Royea \& Nicol, 2019). 
This article presents the results from a questionnaire administered to participating teachers with an aim to capture their perspective on teaching of STEM scaffolded by robotics, before and after implementation of botSTEM activities. The focus in the present study is specifically on the possible impact on the preschool teachers and their view of STEM teaching scaffolded by robotics in preschool. The research question governing the analysis is:

- How can in-service preschool teachers' self-efficacy of the STEM disciplines and their expressed experiences of STEM teaching scaffolded by robotics be described after implementation of botSTEM practices?

\section{Methods}

Teaching using the botSTEM activities have been investigated in Sweden and Spain. Planning discussion with the preschool teachers in both countries respectively about the intended object of learning led to implementations of teaching. The teachers were asked in questionnaires and interviews as described below about their views of STEM and STEM teaching supported by robotics and also to reflect on their teaching, i.e. their views of the enacted object of learning.

\section{The Swedish setting}

In Sweden, preschools are divided in groups of children with a work-team in charge. The work-teams (3-5 persons) consist of at least one preschool teacher with a first cycle university degree and childcare takers with a specialist upper secondary school degree. The Swedish preschool is goal-directed with teachers having to provide favourable conditions for children's learning based on both content and pedagogical knowledge. The Swedish national curriculum for preschool states that education should be based on a holistic approach to children and the needs of children, in which care, development and learning from a whole should be considered. In an early version of the curriculum, science was focused only in terms of nature and biology but during the curriculum revision in 2010, science from the point of 'simple chemical processes and physical phenomena' was included. Furthermore, from 2019, when a new curriculum was launched, education should also give children the chance to develop 'adequate digital skills' (Swedish National Agency for Education, 2018). More specifically, the curriculum goals to reach for concerning STEM content are that the preschool should provide each child with the conditions to develop:

- an interest in stories, pictures and texts in different media, both digital and other, and their ability to use, interpret, question and discuss them,

- an ability to use mathematics to investigate, reflect on and try out different solutions to problems raised by themselves and others,

- an understanding of space, time and form, and the basic properties of sets, patterns, quantities, order, numbers, measurement and change, and to reason mathematically about this,

- an ability to discern, express, investigate and use mathematical concepts and their interrelationships, 
- an understanding of relationships in nature and different cycles in nature, and how people, nature and society affect each other,

- an understanding of how different choices people make in everyday life can contribute to sustainable development,

- an understanding of natural sciences, knowledge of plants and animals, and simple chemical processes and physical phenomena,

- an ability to explore, describe with different forms of expression, ask questions and discuss science and technology,

- an ability to discover and explore technology in everyday life, and

- an ability to build, create and construct with the help of different techniques, materials and tools.

In both Sweden and Spain, preschool has a long tradition in working thematically, and activities are never divided into school subjects. Consequently, we describe the teaching of integrated STEM 'disciplines' instead as integrated STEM 'content areas', when referring to the preschool setting. As described above, STEM and robotics have quite recently been strengthened in the national curriculum, leading to a demand for professional development in both areas since many preschool teachers express a lack of knowledge and teaching experience in relation to them. The botSTEM practices and pedagogical framework can be seen as a response to this demand.

To finalise we can say that preschool teachers have varying education focused on STEM and robotics. Some have attended a recent preschool teacher education where science and digitalisation are part of the courses, and some have an older preschool education where STEM education was very limited. Some of the participating preschool teachers have taken part of a professional development program focusing science in preschool and others have taken a 7.5 credit university course in science in preschool. Yet others have a limited education focused on STEM, but in several cases a keen interest to improve their knowledge about STEM and STEM education research.

\section{Data collection in Sweden}

In the botSTEM project, three researchers and five preschools have been involved in the implementation and evaluation of toolkit activities, see Table 1 for details of the data collection. In a first step, botSTEM was introduced to preschool teachers during on-going professional development courses in science, run by the researchers, and ten preschool teachers chose to join the project. An introductory meeting was held with preschool teachers and researchers, where the aim, theoretical background, and design of the botSTEM project were introduced. Following the meeting, each preschool teacher chose an activity from the toolkit, adapted it, and performed it together with a group of children (varying between two and six in numbers). The activities were filmed, either by a present researcher or by a colleague. Ten months after the activity, the preschool teachers were asked to complete an on-line questionnaire about their lived knowledge and thoughts about STEM and robotics, in relation to before and after the

Table 1 Preschool teachers participating in the project

\begin{tabular}{lll}
\hline Country & Preschools & Teachers \\
\hline Sweden & 5 & 10 \\
Spain & 3 & 11 \\
\hline
\end{tabular}


botSTEM project. The questionnaire consists of four parts: (1) background information, (2) self-efficacy questions, (3) multiple-choice questions, and (4) open-ended questions. The purpose of the questionnaire was to uncover the participants' prevailing experiences of STEM and robotics, attitudes to the STEM field of knowledge and its role in a preschool context, as well as any changes over time of self-efficacy (Appendix A). The self-efficacy part has a Likert-scale structure and the respondents are asked to estimate their knowledge of the different science content areas and science teaching.

\section{The Spanish setting}

In Spain, Early Childhood Education is voluntary and divided into two cycles, a first from birth to 3 years, and a second from 3 to 6 years of age. In the latter educational stage, the aim is to contribute to the physical, affective, social, and emotional development of children from a global approach, that is, the contents are organized in interrelated areas. The methodological approach to these areas should be based on the experience of children and on play, within an atmosphere of affection and trust that helps to enhance self-esteem and social integration.

Focusing our attention on the second cycle and on the community of Castilla y León, since all the Spanish participants belong to that region and stage (3-6 years old children), it is convenient to point out that the content areas are three: Self-knowledge and autonomy, Knowledge of the environment and Languages: Communication and representation. Three areas in which learning is organized with the aim of bringing the everyday world closer to the children so that they can interpret it, give it meaning and participate in it.

Although in the curriculum of this second cycle, there are no specific references to learning science or STEM, the area entitled: Knowledge of the environment, establishes objectives closely related to this field of knowledge such as:

- Identify the properties of objects and discover the relationships that are established between them through comparisons, classifications, series, and sequences.

- Get started in the concept of quantity, in numerical expression and in arithmetic operations, through manipulation and experimentation.

- Observe and actively explore their environment and show interest in significant events and situations, identifying their consequences.

- Know some animals and plants, their characteristics, habitat, and life cycle, and assess the benefits they bring to health and human well-being and the environment.

- Take an interest in the physical elements of the environment, identify their properties, possibilities of transformation and usefulness for life and show attitudes of care, respect, and responsibility in their conservation.

Likewise, in order to achieve these last two objectives, the suitability of using research processes in an 'incipient way' is detailed, in which procedures such as observation, experimentation, obtaining and analysing results and drawing conclusions can be implemented.

On the other hand, this curriculum also explicitly establishes that from these early stages of schooling, it is important to introduce experiences related to ICT and dedicates an entire block of content to this regard. However, nothing is specified about the introduction of programming at these ages. In this second cycle, a university-trained teacher is in charge of a group, with a maximum of 25 children. 
These educational guidelines published in 2006, also give a very important role to schools, since they are the last responsible for defining and completing the curriculum. A fact that allows greater freedom and dynamism when proposing new projects, as is the case with botSTEM. But nevertheless, it does not promote a common training from universities in the teaching of science, or integrated STEM education for future teachers of this educational stage. This training remains in the hands of the initiatives of some universities, educational administrations of specific regions (like Castilla y León), and of teachers who seek progress in this area.

\section{Data collection in Spain}

The collaboration established between the researchers of the botSTEM project and the educational centres of early childhood education in Spain began in 2018. Initially, four schools, after knowing the general objectives of the project and those that were expected to be achieved with the joint work, decided to actively participate in the implementation of the activities proposed in the toolkit, as happened with the Swedish partners. In total there were two researchers and 11 preschool teachers, divided into three working groups, the participants in this initial phase of the project (Greca Dufranc et al., 2020).

An important aspect to highlight is that these schools have shown a special interest in introducing innovative methodologies related to STEM, robotics, and programming in their educational centres. All of them actively participating in programs fostered by Castilla y León educational administration and Erasmus projects linked to the University of Burgos aimed at training teachers and developing projects that enhance the skills of children in these areas.

After this phase, like the procedure followed in Sweden, the teachers responded to the previously described questionnaire. On this occasion, however, nine of the eleven preschool teachers responded individually to the first two sections of the questionnaire distributed among Swedish teachers (background information and self-efficacy questions), and jointly, through a focus group with each of the working groups, the eleven participants responded to the last two sections (multiple-choice questions and open-ended questions).

\section{The activities}

The botSTEM toolkit involves both non-digital and digital programming activities, the latter including a variety of robots. All digital activities chosen by the Spanish and Swedish preschool teachers involved a Blue-Bot, a small beetle-like robot that can be programmed to go forward, backward, or side-ways, by four buttons on its back. In the activities involving the Blue-Bot, the robot was programmed to 'walk' on a grid on the floor, towards a specific target involving a science phenomenon, that was previously addressed through hands-on activities, using inquiry teaching. The task for the children was then to program the Blue-Bot to walk between e.g. an animal and its food source or the properties of magnets, represented by pictures in the grid. In the non-digital programming activities, the children instead acted as robots, following arrow paths on the floor. 


\section{Analysis}

The demographic questions in the first part of the questionnaire were not used in the analysis due to the low number of participants. The results from the Likert-scale and multiple-choice question are presented and commented on below. The three open-ended questions were analysed with a double-blind comparative strategy by two researchers. The answers to question Give examples of everyday life events that could be the starting point for teaching STEM in preschool were analysed according to categories from Thulin and Redfors (2017). Consequently, and with the aim to find nuances in the answers, a category-based analysis was performed where the answers were categorized into a 'what' or 'how' perspective, a child or teacher perspective and into what disciplines of STEM (Science, Technology, Engineering, Mathematics) were present in the examples given. In addition, a category called Education for Sustainable Development was included to define answers with a more holistic view that did not fit into any of the STEM content areas.

The answers to the questions Describe how you experienced opportunities and obstacles using robotics in your STEM teaching and Describe children's changed knowledge related to your robotics and STEM teaching -give examples was read separately by the two researchers who first made a thematic analysis and identified different themes, or categories, in the preschool teachers' views of STEM and robotics. The researchers met and discussed these categories, with a high level of agreement. A consensus was reached and in a second round of analysis, excerpts representing the different categories were selected. An excerpt was one sentence or several, highlighting a specific category. Also, often a preschool teacher's full answer in several sentences could be divided and grouped into different categories. As a result, in the collection of representative excerpts, one sentence could be designated to one category while another sentence from the same preschool teacher was designated to another category.

\section{Ethics}

Ethical considerations are guided by national recommendations, see for example the Swedish Research Council (2016) or the Agencia Española de Protección de Datos (2020). Written and verbal consent from teachers and caregivers have been collected and trust, virtue and confidentiality have been keywords in the data collection and analysis. A sensitive approach to children and teachers were undertaken and children were asked for verbal consent before filming. All names in the excerpts are pseudonyms to ensure the participants' anonymity.

\section{Results}

The results section is introduced by the presentation of the quantitative analysis of the preschool teachers' expressed self-efficacy of the STEM disciplines and robotics (R). Thereafter are the categories from the qualitative thematic analysis of the responses to the open questions presented. The categories jointly represent the answer to the research question's second part about the teachers expressed experiences of the implemented teaching. 


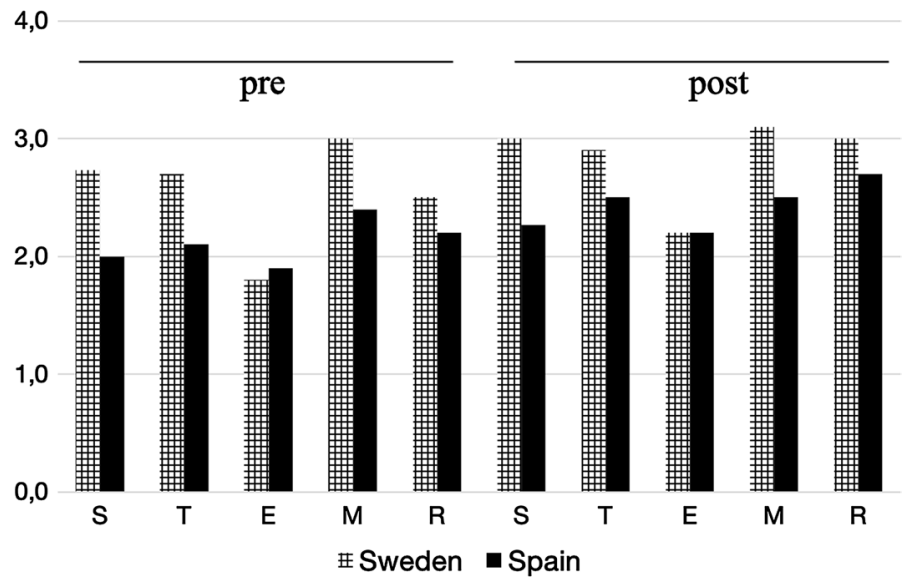

Fig. 2 Preschool teachers' self-efficacy in STEM content knowledge before and after the botSTEM project

4,0

pre

post

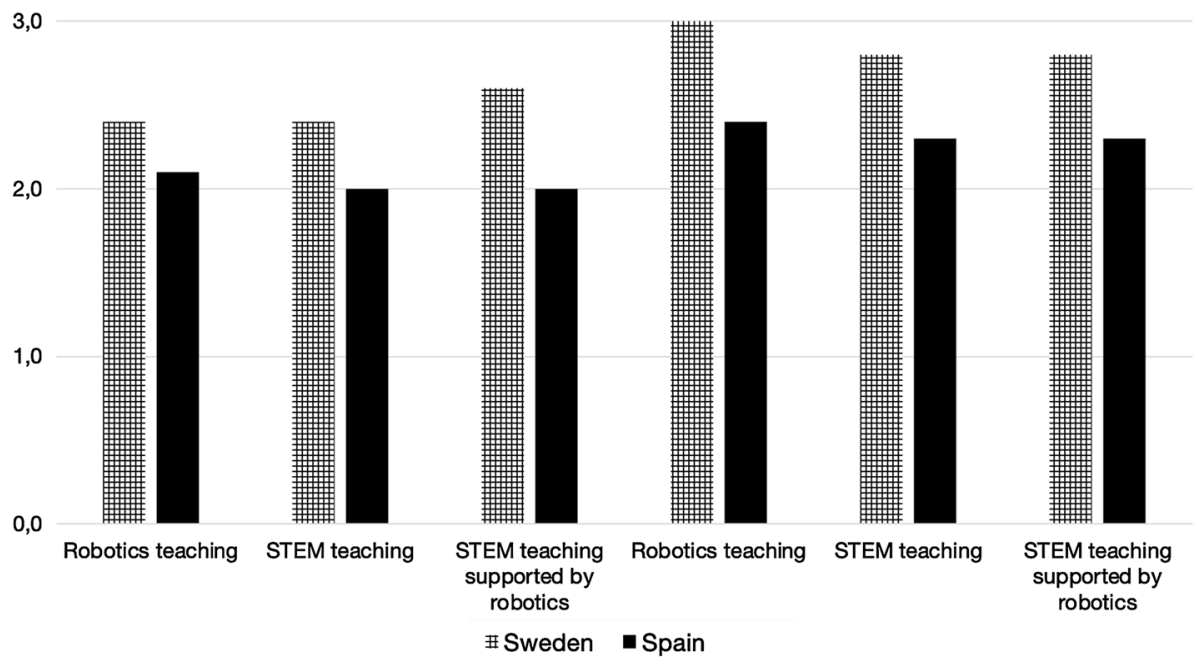

Fig. 3 Preschool teachers' self-efficacy in STEM teaching before and after the botSTEM project

\section{Preschool teachers' self-efficacy in relation to knowledge and teaching of the STEM content areas}

The preschool teachers' self-valued knowledge of STEM and STEM teaching is presented in Figs. 2 and 3. Wilcoxon signed-rank test was applied comparing the teachers' stated self-efficacy for content knowledge before and after by country (Fig. 2) and 
significative differences in self-efficacy were found for Engineering knowledge for Swedish teachers and for Robotics knowledge for Spanish teachers.

Similarly Fig. 3 presents the preschool teachers' self-efficacy for STEM and robotics teaching before and after the botSTEM project and from the Wilcoxon signed-rank test significative differences were found for both, Swedish and Spanish teachers' self-efficacy before and after the project regarding STEM teaching supported by robotics. However, regarding Robotics teaching only for the Spanish teachers. Although there is no statistically significant difference detected, data from both countries show an increase in self-efficacy.

\section{Preschool teachers' examples of everyday life events as starting point for teaching STEM}

The open-ended questions were answered by the preschool teachers after completion of the STEM teaching. The first question was formulated Give examples of everyday life events that could be the starting point for teaching STEM in preschool. The examples given by the preschool teachers were categorised according to the following four perspectives:

1. What, or How, or What/How, depending on if the nature of the answer pointed towards a specific content of teaching, an action of teaching, or both. In both Sweden and Spain, the preschool teachers preferably gave examples of what content the teaching could comprise, as seen in this answer by a Swedish preschool teacher:

Weather and season, which can be connected to light, heat, change in nature and the chemical processes that are part of this change. [...] (Swedish preschool teacher, categories W-T-S-S)

Other content examples given by the preschool teachers were work with robots, food waste, mixtures, water, and culturing of plants.

A single How-perspective on the teaching was less evident in the answers but an example is expressed by a Swedish preschool teacher:

To make use of all materials in preschool that give the children a possibility to their own experiences and discoveries about how they themselves can affect their environment and play. [...] (Swedish preschool teacher, categories H-T-S/C-S)

Less apparent in the material was also a combined What/How-perspective. However, a Spanish preschool teacher answered:

Mixtures. Working with them why I have powder and it disappears, what has happened to it? And if I leave it in the window, it crystallizes. The water has gone and now I have crystals. (Spanish preschool teacher, categories W/H-C/T-C-S).

2. Children, or Teacher, or Children/Teacher, depending on if the answer focused children's or the teacher's perspective, or both. Interestingly, all Spanish preschool teachers gave examples from the children's viewpoint while all Swedish preschool teachers focused their role as teachers, in their reasoning: 
States of water. Children love to freeze things. They like to put a stick in the water and see how the next day it is trapped. (Spanish preschool teacher, categories W-CC-S).

[...] Knowledge of how food is created is an important knowledge in many ways, we teach man's dependence on nature and dependence on a healthy nature that can produce food for us. (Swedish preschool teacher, categories W-T-S-S).

A combined perspective is seen in the following statement, involving a Blue-Bot. As mentioned in the Methods section, the Blue-Bot is a small, beetle-like robot that can be programmed to 'walk' in four different directions with four buttons on its back:

Exploration with help of Blue-Bot about inclining plane and how different surfaces give different friction where the children get to make hypotheses. To let robotics in the form of Blue-Bot be an interesting tool for to meet fact knowledge about science, for example animals. [...] (Swedish preschool teacher, categories W/H-C/T-C-S/TE/R)

3. Society, or Children now, or Society/Children now. A third perspective on the answers was whether they reflected a view on teaching related to children's interest here and now, or a society perspective more in the future. The Spanish preschool teachers focused children here and now while the Swedish preschool teachers' answers were more evenly dispersed between the society and 'children now' perspective:

I am thinking about a sledge, things that they do daily, it is a polished surface. (Spanish preschool teacher, categories W-C-C-S)

[...] To use drawing paper and paper towels without wasting for to together save the preschool's money and related to a joint responsibility for nature's resources. (Swedish preschool teacher, categories H-T-S-ESD)

4. Science (S), Technology (T), Engineering (E), Mathematics (M), Robotics (R), or Education for Sustainable Development (ESD). This fourth and final category aimed at investigating what STEM disciplines could be identified in the preschool teachers' examples. Notably, the science discipline dominated in both countries, a large spread with examples ranging from animals, water phases, air, mixtures, friction, and culturing, to children's learning of the scientific process in terms of making hypotheses and testing them. Technology and Engineering was only described by one preschool teacher, in the form of stable bridge construction to match a Blue-Bots weight and movement. Three preschool teachers gave examples related to robotics, when they wrote about teaching sequence thinking and programming, and making the children reflect about different robots that are present in society. In addition, in the material a few examples of a more holistic, environmental view on what teaching of STEM should comprise, was identified. These did not fit into any of the specific STEM disciplines, whereby the category ESD was included.

\section{Preschool teachers' experienced opportunities and obstacles when using robotics in STEM teaching}

The answers to the question Describe how you experienced opportunities and obstacles using robotics in your STEM teaching is below presented as themes of possibilities and obstacles respectively, experienced by the preschool teachers. 


\section{Possibilities experienced by the preschool teachers when working with robotics in STEM}

After a phenomenographic analysis was performed (Marton, 2014), four themes of possibilities were identified in the answers. According to the preschool teachers, robotics contributes to teachers' planning of STEM teaching, instigates children's enthusiasm, stimulates children's knowledge, and stimulates children's agency. Each category is in the following introduced and exemplified by one or more quotes from the preschool teachers.

From the answers, it was evident that preschool teachers interpreted 'robotics' in a wider sense, including digital tools in general. The examples given of how it effects their planning relate to documentation, projectors, applications, and internet, involved in their teaching. The botSTEM project itself is considered helpful with its "free" arrangement where the preschool teachers could choose themselves what activities suited them and their child group. One preschool teacher expresses the opportunities that lie in being attentive to children's own thoughts in the planning of teaching activities, in the quote below, chosen to exemplify the category.

- Robotics contributes to teachers' planning of STEM teaching

Great possibilities if you as a teacher have an open mind and listen to the children's reflections (Swedish preschool teacher)

Several preschool teachers mention children's enthusiasm for robots. It is easy to get children involved in teaching activities when a robot is present, and the robot can also provide an entrance for children to engage in other STEM content areas.

- Robotics instigates children's enthusiasm

They are very curious. (Spanish preschool teacher)

Since children find robotics interesting you can attract them to meet science (Swedish preschool teacher)

The preschool teachers also report an increased knowledge in children when they program robots.

- Robotics stimulates children's knowledge

It is a game for them. [...] At the beginning it's difficult for them, but then you can see how they can do two or three different things, they are thinking about it. It is very interesting, very beautiful. (Spanish preschool teacher)

Many examples are given that involves a higher degree of children's agency than before. They handle the Blue-Bot in a more confident way, they are more independent and program without the help of preschool teachers and they are not afraid to try new ways, with the robot. What is interesting is also the connection the preschool teachers see to science and a scientific work process. 
- Robotics stimulates children's agency

The children have an investigative approach (Swedish preschool teacher)

The children take initiative to testing the Blue-Bot on new surfaces and in new environments (Swedish preschool teacher)

\section{Obstacles experienced by the preschool teachers when working with robotics in STEM}

Interestingly, the obstacles described were fewer than the possibilities, in the material. They could broadly be divided into structural, technical or children's obstacles, experienced by the preschool teachers.

The preschool teachers described too little time to prepare or carry out the activity, too large groups of children, too few robots at hand, as obstacles. In the analysis, these factors were considered structural and part of the overall preschool condition, and they were the most common among the obstacles mentioned. A Spanish preschool teacher described the role of the room chosen for the robotics teaching, and from our work with the preschool teacher, we know that the preschool she refers to makes use of a specific robotics room where the children go to learn robotics. This is where the robots are kept, and they are not supposed to leave the room. What the preschool teacher points to is the conflict between keeping the robots 'safe' on one hand, and not being able to be spontaneous in the teaching and exploration of them, on the other. Not being able to bring them to another classroom also made the integration of robotics with STEM disciplines more difficult.

\section{- Structural obstacles}

Robots... I see how Science, Tech, Engineering and Mathematics can fit... when you are in a class talking about these, things emerge spontaneously, but when it comes to robots... it is time to go to the 'robotics classroom' and work there exclusively with robots. (Spanish preschool teacher)

Also, pure technical problems with a "messed up" and vulnerable technology are mentioned in the answers.

- Technical obstacles

It's a disadvantage if the work builds on an expectation that the technology should work and deliver. It's vulnerable. (Swedish preschool teacher)

A few answers addressed the children's limitation in the teaching situation.

- Children's obstacles

They (the children) can't generalize. (Spanish preschool teacher) 


\section{Preschool teachers' descriptions of children's changed knowledge related to the teaching of robotics and STEM}

The third open question in the questionnaire read Describe children's changed knowledge related to your robotics and STEM teaching - give examples. The answers reflected what was expressed also for the experienced possibilities in relation to robotics in STEM teaching and could be grouped into six categories, two with a focus on children's changed knowledge in relation to STEM, Children's interest in STEM has increased and Children's understanding in STEM has increased, and four to robotics, Children's understanding in robotics has increased, Robotics supports children with special needs, Robotics supports children's interactions with each other and Robotics supports children's agency.

The preschool teachers described a great interest among the children for the chosen STEM activities. One preschool teacher detected an increased interest in mathematics. Another example involved a growing interest for science, when a group of children were fascinated by magnets and wanted to bring the magnetic preschool material home to continue exploring it. Also, in Spain, parents testified of their children's interest and how the investigations continued after preschool and in addition, reports on how some parents' curiosity in STEM teaching increased through the botSTEM project are present in the material. Also interesting is that a corresponding category for an increased "interest in robotics" was not found in the material. One can speculate if this is due to a large interest for robots from the beginning.

- Children's interest in STEM has increased

Parents have told us that their children built ramps from their beds, that is, they play with it at home. (Spanish preschool teacher)

Their parents were excited about how they (children) liked it. [...] parents asked us about how we made it, about what kind of surfaces we used to make the car go faster and slower... (Spanish preschool teacher)

Many examples were given of how the children's understanding of specific science phenomena has increased, after the botSTEM project and a similar increase in understanding is reported for integrated mathematics.

\section{- Children's understanding in STEM has increased}

It became easier to get the children to dress in the right outdoor clothes after they had formulated hypotheses about weather and clothes (Swedish preschool teacher)

It is not smoke anymore. Now it is steam. (Spanish preschool teacher)

Children are making connections between mathematics and programming of bluebots (Swedish preschool teacher)

Preschool teachers are also reporting on an improved understanding of, and confidence in, robotics concepts.

- Children's understanding in robotics has increased 
The children learned you must program in the right order (Swedish preschool teacher)

The children are more secure in programming (Swedish preschool teacher)

The sequences were anticipated by children who were not using the robot in that moment (Spanish preschool teacher)

An unexpected effect described involved children with special needs. One preschool teacher told us during a visit at the preschool about a child that normally had difficulties interacting with people and taking turns. In activities with the Blue-Bot the child had found a way to play with the other children, and the preschool teacher observed how taking turns when programming the robot was no problem for the child. She interpreted this as the Blue-Bot motivated the child and constituted a fun object to interact with others around, as well as a useful tool for learning social skills.

- Robotics supports children with special needs

Robotics benefits children with concentration difficulties, a large interest (Swedish preschool teacher)

Children with special needs (autism) have developed and established interactions with each other (Swedish preschool teacher)

Besides being beneficial for children with special needs, the preschool teachers described this valuable effect of children in general. When working with robotics, children at the same time learned to interact with each other in the process.

- Robotics supports children's interactions with each other

The children teach each other, co-operate (Swedish preschool teacher)

The children ask more often now if they can work together, with robotics (Swedish preschool teacher)

Reports on how children developed curiosity, creativity, and courage from the activities as well as the perception of mistakes as given rise to new opportunities rather than failure are given, which we consider examples of a growing agency in children. In the material, there is also example of how children's learning is reflected in their free play.

- Robotics supports children's agency

The activities were reflected in children's play in everyday life (Swedish preschool teacher)

This robot is crazy, where does it go? We tell them where they have to go. If we make a mistake, nothing happens. You can do it again (Spanish teacher citing a child's comment) 


\section{Discussion}

The use of robots in preschool has become more frequent following the development of curricula in the two investigated countries. With the introductions of a didactical framework and teaching activities from the botSTEM project (Greca et al., 2020), uses of robots have been given fruitful learning contexts, i.e. STEM contexts. The design-based implementation of the botSTEM activities has enabled preschool teachers to experience STEM teaching in new ways. They have seen many positive aspects for children's interactions with each other and agency. Also, positive aspects for inclusion related to special education have been reported by the preschool teachers.

STEM teaching and robotics (programming) are concepts often used indistinctly. When thinking in terms of using robotics as means of STEM teaching, new perspectives are opened up where specific objects of learning (Marton, 2014; Marton \& Booth, 1997) more easily can be formulated for integrated STEM teaching (Ortiz-Revilla et al., 2020). Hence, it has been found that it is important that teachers differentiate the concepts and identify robotics (programming) as a tool to scaffold STEM teaching, and not as a synonym of STEM.

There were significant changes detected for the preschool teachers' perceived knowledge of engineering and robotics, but only small increases for the S, T and M disciplines. In the case of robotics, a significant difference was found for Spanish teachers, who had never used robots before, neither imagined children could use them for pedagogical purposes when the project started. For science, this could be due to the large spread of views concerning science content articulated by the preschool teachers. The spread could in part be explained by that the Swedish preschool teachers previously had attended professional development courses in science, possibly widening their understanding and 'repertoire' of science examples. This could also explain the initial high self-efficacy in science education among the Swedish teachers compared to the Spanish teachers. Although the Spanish preschool teachers had a more limited experience of science in their academic and professional career development, they gave examples of phenomena in the fields of chemistry and physics and not only in biology, which has been reported to sometimes be the case when preschool teachers are unexperienced in science (Thulin \& Redfors, 2017). Hence, a broad definition of science among preschool teachers could be said to indicate knowledge and experience, but interestingly, it could also indicate a lack of the same. In previous research work, Thulin and Redfors (2017) showed that student preschool teachers' views of science constituents were widely spread before entering a course focusing on science in their preservice education. However, after completion of the course this changed, and the conclusion was that an increased knowledge of science in the context of preschools was the main reason. In contrast, the detected improvement concerning self-efficacy of STEM teaching during this project indicates the importance of the scaffolding of the design-based implementation and the introduction of a teaching framework, in this case based on variation theory (Marton, 2014; Marton \& Booth, 1997). The important role of a theoretical framework for sustainable development of teaching is in concurrence with earlier work (cf. Chu et al., 2019).

Related to their expressed experiences of STEM teaching within botSTEM activities, preschool teachers described the great interest aroused among children for the chosen STEM activities, emphasising their improvements in their understanding of science, maths and robotics concepts. This can be seen as an expression of teachers' positive experiences with the material. Nevertheless, they also highlight some obstacles, like too little time to 
prepare or carry out the activity, too large groups of children, and too few robots at hand. Something that is frequently mentioned in the literature as structural of the overall preschool condition and for STEM activities in particular (Yıldırım, 2021).

An interesting statement from one of the preschool teachers, in the questionnaire but also told verbally to one of the researchers, involved how s/he experienced a positive development in a child with special needs. The child is diagnosed with a neurodevelopmental disorder and finds it difficult to interact with peers and to concentrate for longer periods of time. In teaching situations involving the child programming the Blue-Bot, the preschool teacher noticed a high level of concentration alongside a playful interaction with other children. This observation is in line with what was reported recently in a literature review of educational robotics used by children with neurodevelopmental disorders (Pivetti et al., 2020). Pivetti et al. (2020) analysed 15 articles, nine of them described improved engagement and six of them reported improved communication/interaction with peers. This points to important aspects and benefits of teaching robotics in preschool.

\section{Conclusion}

The process of a design-based implementation of integrated STEM teaching activities supported by robotics has led to new knowledge concerning conditions for STEM teaching in preschools and use of robotics. It has been seen that preschools teachers initially somewhat at loss at what to do, have developed their teaching competence with following increase of self-efficacy concerning STEM and STEM teaching. The project has also pinpointed the need for supported long-term professional development for an advancement of STEM teaching in preschools. But, when such professional development structures are in place, progress can be expected. 


\section{Appendix A: Questionnaire for preschool teachers-translated}

1. In order for us to be able to compare results given at different times during the three-year botSTEM project, you need to fill in the following.
1.1 Name:
1.2 Education:
1.4 Age:
1.5 Gender: Female
1.3 Employed as:
Male

2. Evaluate how you experienced your knowledge in STEM and robotics before botSTEM

2.1 My own knowledge of physics felt

Very good Good Insufficient Very inadequate

2.2 My own knowledge of biology felt

Very good Good Insufficient Very inadequate

2.3 My own knowledge of chemistry felt

Very good Good Insufficient Very inadequate

2.4 My own knowledge of technology felt

Very good Good Insufficient Very inadequate

2.5 My own knowledge of engineering felt

Very good Good Insufficient Very inadequate

2.6 My own knowledge of mathematics felt

Very good Good Insufficient Very inadequate

2.7 My own knowledge of robotics felt

Very good Good Insufficient Very inadequate

3. Evaluate how you experience your knowledge in STEM and robotics now, after having worked with the botSTEM activities

3.1 My own knowledge of physics feels

\begin{tabular}{|c|c|c|}
\hline \multirow{2}{*}{\multicolumn{3}{|c|}{$\begin{array}{l}\text { Very good Good Insufficient } \\
\text { 3.2 My own knowledge of biology feels }\end{array}$}} \\
\hline & & \\
\hline Very good & Insufficient & Very inadequate \\
\hline \multicolumn{3}{|c|}{ 3.3 My own knowledge of chemistry feels } \\
\hline Very good & Insufficient & Very inadequate \\
\hline \multicolumn{3}{|c|}{ 3.4 My own knowledge of technology feels } \\
\hline Very good & Insufficient & Very inadequate \\
\hline \multicolumn{3}{|c|}{ 3.5 My own knowledge of engineering feels } \\
\hline Very good & Insufficient & Very inadequate \\
\hline \multicolumn{3}{|c|}{ 3.6 My own knowledge of mathematics feels } \\
\hline Very good & Insufficient & Very inadequate \\
\hline \multicolumn{3}{|c|}{ 3.7 My own knowledge of robotics feels } \\
\hline Very good & Insufficient & Very inadequate \\
\hline
\end{tabular}

4. Evaluate how you experienced your knowledge in didactics of robotics and STEM before botSTEM

4.1 My own knowledge of planning, teaching and evaluating a robotics activity felt

Very good Good Insufficient Very inadequate

4.2 My own knowledge of planning, teaching and evaluating a STEM activity felt

Very good Good Insufficient Very inadequate

4.3 My own knowledge of planning, teaching and evaluating a STEM activity scaffolded by robotics felt

Very good Good Insufficient Very inadequate

5. Evaluate how you experience your knowledge in didactics of robotics and STEM now, after having worked with the botSTEM activities

5.1 My own knowledge of planning, teaching and evaluating a robotics activity feels Very good

Good Insufficient

Very inadequate 
5.2 My own knowledge of planning, teaching and evaluating a STEM activity feels Very good Good Insufficient Very inadequate 5.3 My own knowledge of planning, teaching and evaluating a STEM activity scaffolded by robotics feels

Very good Good Insufficient Very inadequate

6. Here are some questions about Science. Mark the answer that you think is best suited to each of the questions. Mark one answer per question.

6.1 How do you like to describe the content area Science; What is Science to you?

- Science is about the nature we are living in, from animals to plants and humans. How everything affects everything else.

- To me science is chemistry, biology and physics, labwork and so on.

- Science is a broad subject including: Biology, Chemistry, Physics, Technology, environment and mathematics. Science explains how the world and the universe works.

- Science is something everybody must know.

6.2 How would you describe your own view of science?

- Have not had a positive view of the science subjects. Just remember terribly boring physics lessons in secondary school, that you just want to forget.

- I can think that some things are interesting, but I do not have a big interest.

- I am positive to science and think it is an interesting subject.

6.3 What do you think Science is about in preschool?

- Decomposition like in the compost, bugs and crawlers, leaves and trees, what animal that eats what and so on.

- It is to discover, investigate, study and test scientific phenomena or to discover the living things in a forest or in a lake. To watch a star form.

- That children get to experience different phenomena in nature and reflect over these. Like changes in a compost, changes in trees during different seasons, decomposition, to do experiment.

6.4 What is especially important to consider while working with Science in preschool?

- To work with it on the children's level and with things they have an interest in. That the children get to test different things.

- To know what you talk about by finding out the facts before teaching the children.

- Get the children to help so that they can join in and explore, and make it interesting and exciting.

6.5 Why is Science justified in preschools?

- The older children in school do not get good enough grades $=$ bad interest. Therefore we need to increase their interest early in order for teenagers to better their results and grades.

- It is important to teach the children in time about what is happening around them, why and how things happen.

- So the children get to know and in the future will be able to influence and that they themselves shall have opportunities to investigate and discover now.

7 Concluding open response questions

7.1 Give examples of everyday life events that could be the starting point for teaching STEM in preschool.

7.2 Describe how you experienced opportunities and obstacles using robotics in your STEM teaching.

7.3 Describe children's changed knowledge related to your robotics and STEM teaching - give examples. 
Acknowledgements We acknowledge support from ERASMUS+ 2017-1-ES01-KA201-038204. We also thank the participating preschool teachers for dedicating time to the project and for sharing their experiences with us.

Authors' contributions MF and AR designed the questionnaire, collected and analysed the Swedish data and identified the categories presented for the open-ended questions in the questionnaire. MF and AR were major contributors to writing the manuscript. IMG and EMGT collected and analysed the Spanish data according to the categories described for the open-ended questions, and IMG and EMGT contributed to writing the manuscript. All authors read and approved the final manuscript and the order of authors.

Author reference

Greca Dufranc, I. M., García Terceño, E. M., Cronquist, B., Fridberg, M., \& Redfors, A. (2020). Robotics and early-years STEM education - The botSTEM framework and activities. European Journal of STEM Education, 5(1), 01. https://doi.org/10.20897/ejsteme/7948.

Funding Open access funding provided by Kristianstad University. ERASMUS + 2017-1-ES01KA201-038204, co-funding Kristianstad University and University of Burgos.

Availability of data and materials The datasets used and/or analyzed during the current study are available from the corresponding author on reasonable request.

\section{Declarations}

Competing interests The authors declare that they have no competing interests.

Open Access This article is licensed under a Creative Commons Attribution 4.0 International License, which permits use, sharing, adaptation, distribution and reproduction in any medium or format, as long as you give appropriate credit to the original author(s) and the source, provide a link to the Creative Commons licence, and indicate if changes were made. The images or other third party material in this article are included in the article's Creative Commons licence, unless indicated otherwise in a credit line to the material. If material is not included in the article's Creative Commons licence and your intended use is not permitted by statutory regulation or exceeds the permitted use, you will need to obtain permission directly from the copyright holder. To view a copy of this licence, visit http://creativecommons.org/licenses/by/4.0/.

\section{References}

Agencia Española de Protección de Datos (2020). https://www.aepd.es/sites/default/files/2020-01/codigoetico.pdf. Accessed 15 of March, 2021.

Ali, M. M., Yager, R. E., Hacieminoglu, E., \& Caliskan, I. (2013). Changes in student attitudes regarding science when taught by teachers without experiences with a model professional development program. School Science and Mathematics, 113(3), 109-119. https://doi.org/10.1111/ssm.12008

Bagiati, A., Yoon, S. Y., Evangelou, D., \& Ngambeki, I. (2010). Engineering curricula in early education: Describing the landscape of open resources. Early Childhood Research \& Practice, 12(2), 1-15.

Bybee, R. W., \& Fuchs, B. (2006). Preparing the 21st century workforce: A new reform in science and technology education. Journal of Research in Science Teaching, 43(4), 349-352.

Chu, H.-E., Martin, S. N., \& Park, J. (2019). A theoretical framework for developing an intercultural STEAM program for Australian and Korean students to enhance science teaching and learning. International Journal of Science and Mathematics Education, 17(7), 1251-1266. https://doi.org/10.1007/ s10763-018-9922-y

DeJarnette, N. K. (2012). America's children: Providing early exposure to STEM (Science, Technology, Engineering and Math) initiatives. Education, 133(1), 77-83.

Denessen, E., Vos, N., Hasselman, F., \& Louws, M. (2015). The relationship between primary school teacher and student attitudes towards science and technology. Education Research International, 2015, 1-7. https://doi.org/10.1155/2015/534690

DeWitt, J., \& Archer, L. (2015). Who Aspires to a Science Career? A comparison of survey responses from primary and secondary school students. International Journal of Science Education, 37(13), 21702192. https://doi.org/10.1080/09500693.2015.1071899 
European Union. (2015). Science Education for Responsible Citizenship. Directorate-General for Research and Innovation.

Fridberg, M., Redfors, A., \& Thulin, S. (2017). Preschool children's Communication during Collaborative Learning of Water Phases Scaffolded by Tablets. Research in Science Education, 48(5), 1007-1026. https://doi.org/10.1007/s11165-016-9596-9

Greca Dufranc, I. M., García Terceño, E., Cronquist, B., Fridberg, M., \& Redfors, A. (2020). Robotics and early-years STEM education: The botSTEM framework and activities. European Journal of STEM Education, 5(1), 1-13.

Honey, M., Pearson, G., \& Schweingruber, H. (Eds.). (2014). STEM integration in K-12 education: Status, prospects, and an agenda for research. National Academies Press.

Kermani, H., \& Aldemir, J. (2015). Preparing children for success: Integrating science, math, and technology in early childhood classroom. Early Child Development and Care, 185(9), 1504-1527.

MacDonald, A., Huser, C., Sikder, S., \& Danaia, L. (2020). Effective early childhood STEM education: Findings from the Little Scientists evaluation. Early Childhood Education Journal, 48(3), 353-363. https://doi.org/10.1007/s10643-019-01004-9

Marton, F. (2014). Necessary conditions of learning. Routledge.

Marton, F., \& Tsui, A (red.). (2004). Classroom discourse and the space of learning. Lawrence Erlbaum.

Marton, F. \& Booth, S. (1997). Learning and awareness. Mahwah, NJ: Lawrence Erlbaum Ass.

National Research Council. (2012). A framework for K-12 science education: Practices, crosscutting concepts, and core ideas. The National Academies Press.

National Research Council. (2014). STEM Integration in K-12 education. Status, prospects, and an agenda for research. Washington, DC: The National Academies Press.

Ortiz-Revilla, J., Adúriz-Bravo, A., \& Greca, I. M. (2020). A framework for epistemological discussion on integrated STEM education. Science \& Education, 29, 857-880. https://doi.org/10.1007/ s11191-020-00131-9

Ortiz-Revilla, J., Greca, I. M., \& Arriassecq, I. (2021b). A Theoretical Framework for Integrated STEM Education. Science \& Education. on-Line First. https://doi.org/10.1007/s11191-021-00242-X

Ortiz-Revilla, J; Greca, I. M., \& Meneses-Villagrá, J. (2021). Effects of an integrated STEAM approach on the development of competence in primary education students. Journal for the Study of Education and Development, p. 1-33. https://doi.org/10.1080/02103702.2021.1925473

Pivetti, M., Battista, S., Agatolio, F., Simaku, B., Moro, M., \& Menegatti, E. (2020). Educational Robotics for children with neurodevelopmental disorders: A systematic review. Heliyon, 6(10). https://doi.org/ 10.1016/j.heliyon.2020.e05160.

Royea, D. A., \& y Nicol, C. (2019). Pre-service teachers' experiences of learning study: Learning with and using variation theory. Educational Action Research, 27(4), 564-580.

Swedish National Agency for Education. (2018). Curriculum for the Preschool Lpfö 2018. Stockholm: Skolverket.

Swedish research Council (2016). Good Research Practice. Stockholm: Swedish Research Council.

Thulin, S., \& Redfors, A. (2017). Student Preschool Teachers' Experiences of Science and Its Role in Preschool. Early Childhood Education Journal, 45, 509-520. https://doi.org/10.1007/s10643-016-0783-0

Tytler, R., \& Osborne, J. (2012). Student attitudes and aspirations towards science. In B. J. Fraser, K. Tobin, \& C. J. McRobbie (Eds.), Second international handbook of science education (pp. 597-625). Springer.

Yıldırım, B. (2021). Preschool STEM Activities: Preschool teachers' preparation and views. Early Childhood Education Journal, 49, 149-162. https://doi.org/10.1007/s10643-020-01056-2

Publisher's Note Springer Nature remains neutral with regard to jurisdictional claims in published maps and institutional affiliations. 